\title{
Ionic Surfactants at Air/Water and Oil/Water Interfaces: A Comparison Based on Molecular Dynamics Simulations
}

\author{
Paulina Müller, ${ }^{1}$ Douwe Jan Bonthuis, ${ }^{2}$ Reinhard Miller, ${ }^{1}$ and Emanuel Schneck ${ }^{1}$ \\ ${ }^{1}$ Physics Department, Technische Universität Darmstadt, Germany \\ ${ }^{2}$ Institute of Theoretical and Computational Physics, Technische Universität Graz, Austria
}

(Dated: September 20, 2020)

\section{SUPPORTING INFORMATION}
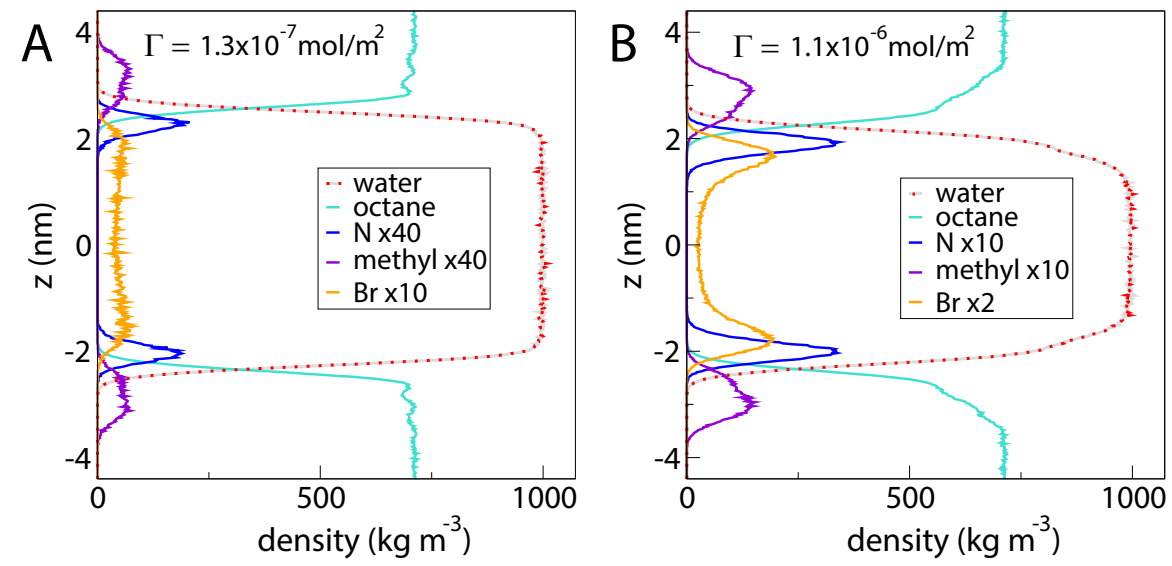

FIG. S1: Comparison between the density profiles obtained with low (A) and high (B) $\mathrm{C}_{12}$ TAB coverage using the Siu forcefield
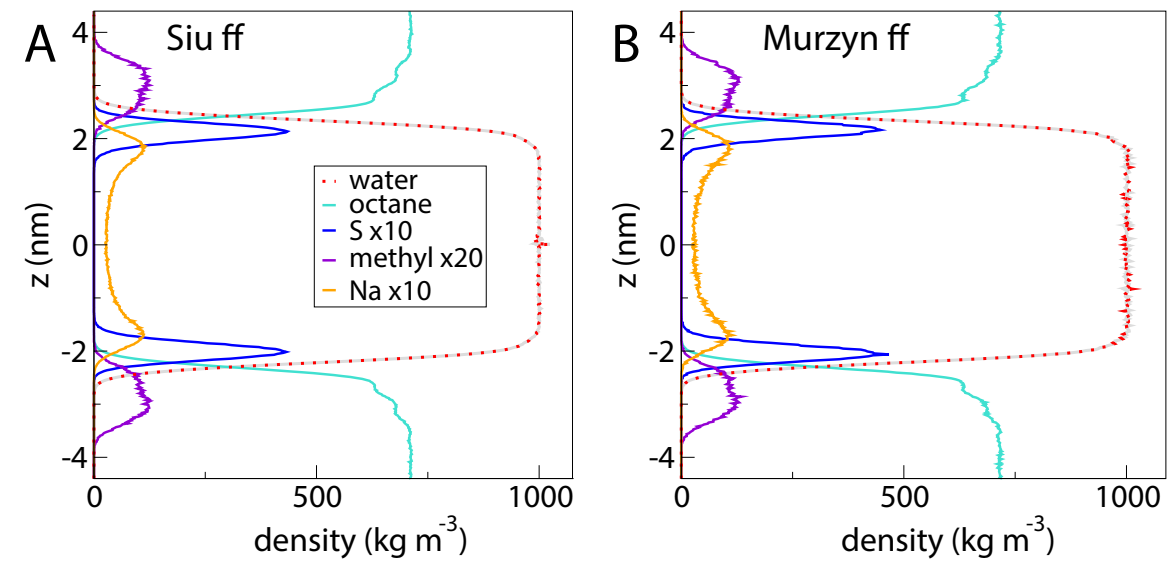

FIG. S2: Comparison between the density profiles obtained with the Siu forcefield (A) and with the Murzyn forcefield $(B)$ at $\Gamma \approx 5 \cdot 10^{-7} \mathrm{~mol} / \mathrm{m}^{2}$. 

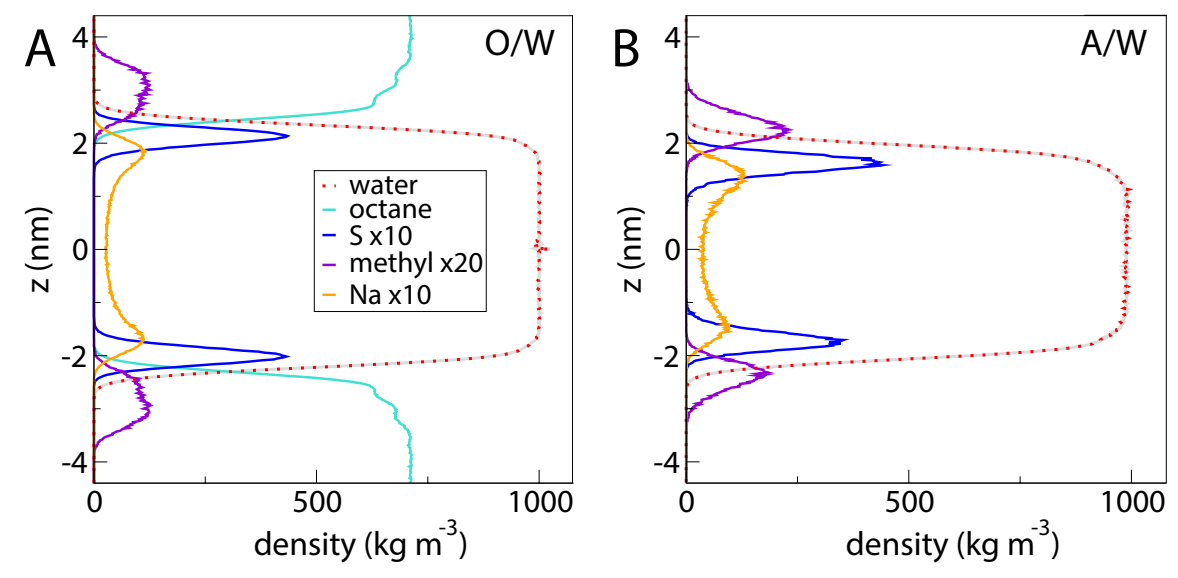

FIG. S3: (A) Time-averaged density profiles of water, surfactant tail methyl groups, surfactant headgroups (represented by the central S atom), $\mathrm{Na}^{+}$counterions, and octane from a simulation of 16 SDS molecules adsorbed to two parallel oil/water $(\mathrm{O} / \mathrm{W})$ interfaces. (B) Density profiles of the same chemical components (except octane) from a simulation of SDS adsorbed to two parallel air/water (A/W) interfaces (same surfactant coverage as in panel A).

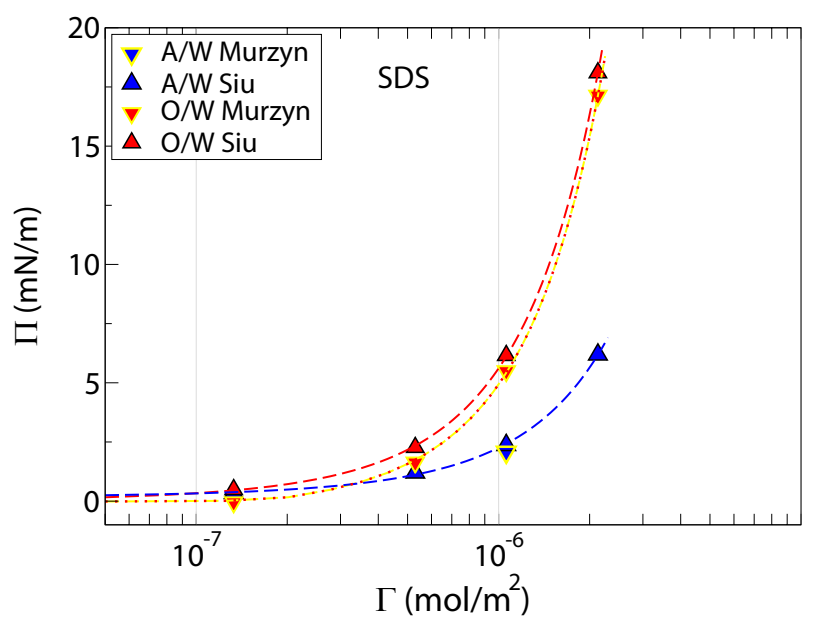

FIG. S4: $\Pi$ for SDS at A/W and $\mathrm{O} / \mathrm{W}$ interfaces as obtained in the MD simulations as a function of $\Gamma$ for the two forcefields by Siu and Murzyn. Lines in panels A and B solely serve as guides for the eye.
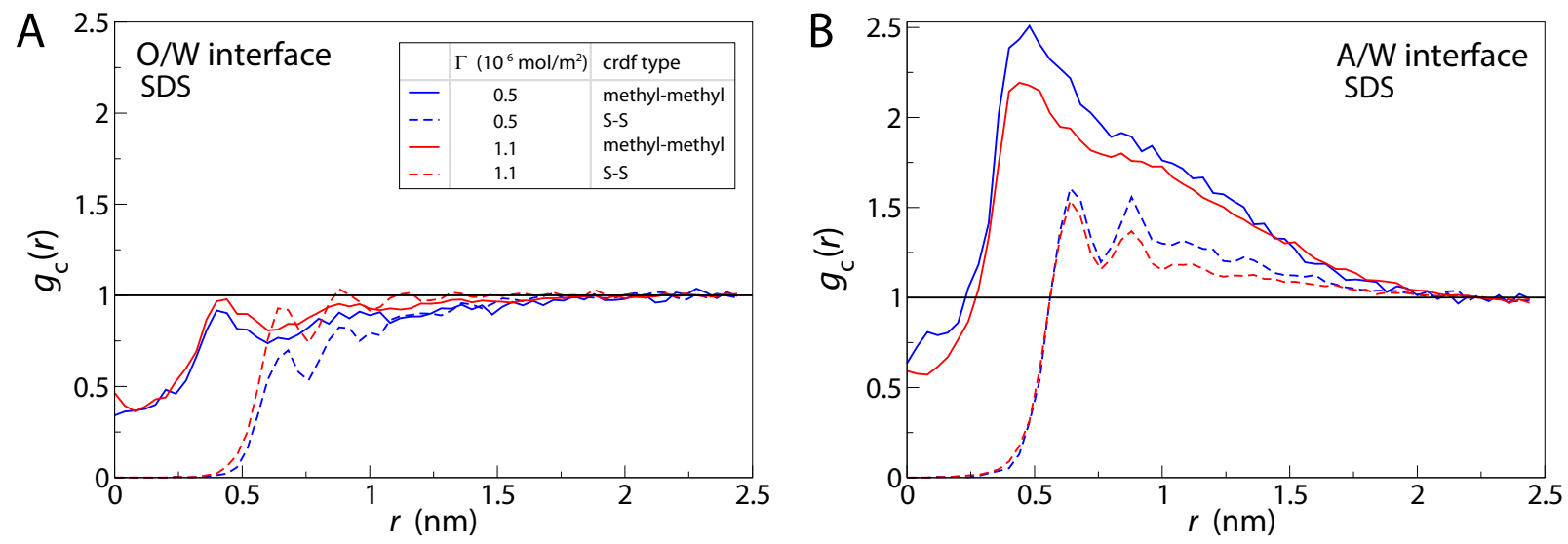

FIG. S5: (A) Cylindrical radial distribution functions (crdfs), $g_{\mathrm{c}}(r)$, of the tail methyl groups and of the headgroups' central $\mathrm{S}$ atoms of SDS at the oil/water $(\mathrm{O} / \mathrm{W})$ interface for selected surfactant coverages $\Gamma$. (B) Same at the air/water $(\mathrm{A} / \mathrm{W})$ interface. The distributions are normalized to converge to unity at large $r$. 


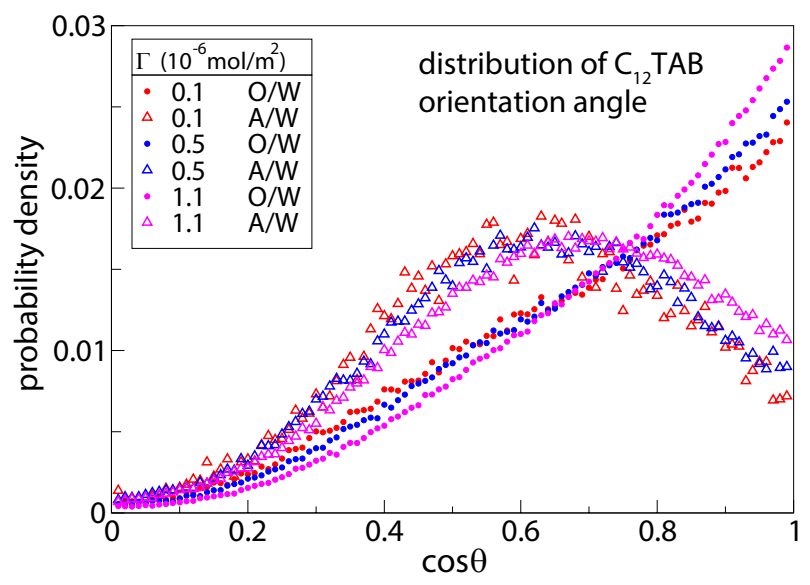

FIG. S6: Distributions of the orientational angle of $\mathrm{C}_{12} \mathrm{TAB}$ at $\mathrm{A} / \mathrm{W}$ and $\mathrm{O} / \mathrm{W}$ interfaces for various surfactant coverages. 